\title{
Tourism donations in sacred settings: An exploratory study of visitor donations in an English cathedral.
}

Pre-refereeing version of a paper published in 2016 at the

\author{
International Journal of Nonprofit and Voluntary Sector Marketing \\ Int. J. Nonprofit Volunt. Sect. Mark. (2016) \\ Published online in Wiley Online Library \\ (wileyonlinelibrary.com) DOI: $10.1002 /$ nvsm.1556 \\ http://onlinelibrary.wiley.com/doi/10.1002/nvsm.1556/abstract
}

Keywords: cathedral tourism, visitor donations, income generation, heritage attractions, sacred buildings.

Paper authors:

Gutic, Jorge and Caie, Eliza.

University of Chichester, Tourism Management Department

Contact details of main author:

Dr. Jorge Gutic

j.gutic@chi.ac.uk

Phone: (01243) 81-2019 Fax (01243) 81-2000

University of Chichester, Tourism Management Department, Bognor Regis Campus, Upper Bognor Road, Bognor Regis, West Sussex, PO21 1HR, United Kingdom 


\title{
Tourism donations in sacred settings: An exploratory study of visitor donations in an English cathedral.
}

\begin{abstract}
Cathedrals have become important visitor attractions, but sacred buildings are typically ancient structures with high conservation and maintenance running costs that their managers struggle to fund. Cathedrals remain underfunded visitor attractions due to the limited opportunities for revenue generation they present. Visitor donations can be an appropriate way to raise much-needed funding, but any commercial activity in a sacred setting must allow the site to maintain its spiritual character.

This paper explored visitor attitudes towards donations in Chichester Cathedral through the use of a self-administered questionnaire. It found that $94 \%$ of respondents were aware of the donation appeals and that $71 \%$ of them went on to make a donation, with the visitors aged 50 to 69 and living within 25 miles of the Cathedral being the most frequent and generous donors. When asked to suggest what they would consider an appropriate donation, $44 \%$ of respondents gave a figure between $£ 1$ and $£ 2$.

This paper suggest measures that Chichester Cathedral managers can implement to increase visitor donations and makes recommendations on how other similar heritage attractions and sacred sites can increase visitor donations. Among these recommendations, the most significant is the identification and targeting of donors' personal meanings to give a donation and in the case of Chichester Cathedral, to specifically target these on their local, middle-aged visitors.
\end{abstract}




\section{INTRODUCTION}

\subsection{Paper Aim}

Religious tourism is an increasing global phenomenon (Shackley, 2001) which is turning cathedrals into important players in the UK visitor attraction market (Churches Tourism Association, 2007). Growth in visitor numbers can be both an opportunity and a challenge for cathedral managers, as it can provide a valuable source of much-needed funding through the collection of donations. This paper explores visitors' behaviour in relation to donations in Chichester Cathedral, and suggest measures that cathedral managers can implement to encourage visitor donations. In addition, the paper makes recommendations on how other similar heritage attractions and sacred sites can increase visitor donations.

This paper also makes a contribution to the limited literature available on visitors' donations in tourism settings by discussing the views of visitors to an English Cathedral on their inclination to make donations for the building upkeep and the appropriateness of donated amounts.

The paper is organised in five sections: the first being a review of the literature discussing the changing role of cathedrals as visitor attractions; their need for revenue generation in order to cope with the increasing visitor demand and visitors' perceptions of donations in relation to places of worship. It then provides a brief description of Chichester Cathedral and the methodology used to collect the information discussed in this paper. This is following this by the results of this research, outlining Chichester Cathedral visitors' behaviour in relation to donations. Finally, it concludes by discussing the study main 
findings and by discussing literature applicable to sacred places in order to make recommendations for increasing donation-related income in cathedrals.

\subsection{The changing role of cathedrals as visitor attractions}

In Britain, a total of seventy cathedrals attract numerous visitors and according to the Association of Leading Visitor Attractions (ALVA, 2014), they constitute an important part of England's visitor attraction market. Indeed, St. Paul's Cathedral and Westminster Abbey were the $9^{\text {th }}$ and $10^{\text {th }}$ most-visited paid attractions in Britain in 2013, receiving over 4 million visits between them, with Canterbury Cathedral also appearing among the top 25 most-visited paid attractions, with more than 1 million visits (ALVA, 2014). The popularity of churches as visitor attractions clearly shows that there is a need for churches and cathedrals to generate sufficient income to maintain the fabric of the site (Shackley, 2006) and to manage all its users in a manner that is sustainable and reconciles the commercial needs of the tourism industry with the religious needs of worshippers (ICORET, 2006).

\subsection{The need for revenue generation in cathedrals}

Despite acting as the historic centrepieces of cities and having enormous financial burdens for their maintenance, British cathedrals receive no financial help from central church funds or government (Shackley, 2006:134). Running costs in order to keep a cathedral open are high, ranging $£ 11.000$ a day for Lincoln Cathedral (Lincoln Cathedral, 2009) to $£ 13.000$ a day for York cathedral (York Minster, 2009). Further to this, it is estimated that Canterbury Cathedral will require $£ 50$ million over a five-year period to carry out essential restoration work to stonemasonry, windows and roof (Canterbury Cathedral, 2007). 
Notwithstanding these high running costs, cathedrals remain underfunded visitor attractions with enormous maintenance bills and few opportunities for generating revenue (Shackley, 2002: 347). Fundraising is a necessary preoccupation for cathedral trustees, and church organisations employ increasingly inventive strategies to gain attention and funds in a competitive charities market (The Giving Campaign, 2007). It is hardly surprising, therefore, that attention is being focussed on schemes to generate an income from increasing visitor numbers; the justification being that "tourism based on cultural heritage can protect and preserve assets which would otherwise have little chance of survival" (Heyerdahl, quoted in Fladmark, 1998:xi).

However, Britain's cathedrals find themselves in a unique position among tourism attractions when it comes to the mechanisms they use to generate revenue for its upkeep. Although it is becoming increasingly common for cathedrals to expect visitors to contribute towards the revenue that ensures the upkeep and maintenance of their buildings, Boniface (1995:100) warns that any commercial activity must allow the site to "stay true to its essence and type". Therefore, although cathedrals may share with other visitor attractions the desire to encourage and welcome visitors, the primary motivation is philanthropic, not financial profit (Shackley, 2001:19). Further, their transformation from places of worship into visitor attractions has made evident that cathedrals "are less than optimally organised and resourced" to meet the different expectations and demands from their various users (Shackley, 2002: 347).

\subsection{Visitors' perceptions of donations in churches}

When considering how to raise revenue from their visitors, most cathedrals have resisted the introduction of entry fees on the grounds that a place of worship should be open to all. Most Deans and Chapters argue that part of their role is to provide a service of 
which free entry is an aspect of the church's mission (Winter and Gasson, 1996:176). Stevens et al. (1995:86) also found that the general public tended to perceive any 'pricing' activity as unfavourable and unsuitable to the aims of the church. Instead, cathedrals have encouraged visitors to make voluntary donations in order to support their upkeep, with a common figure for suggested donations of approximately £2.50 per visitor (Shackley, 2002: 347).

However, a review of the limited available evidence indicates that cathedral visitors are reluctant to make voluntary donations, either due to perceptions of the church as a wealthy institution, or due to the belief that cathedrals receive government support, "while those coming on organised tours think that their tour operators make a contribution to the building visited, which is hardly the case" (Shackley, 2006:138). Voase and Shackley both suggest that cathedrals recommending a suggested voluntary donation as an alternative to charging, "typically receive less than $20 \%$ of the recommended sum per visitor" (Voase, 2007:48), with the "generally accepted figure" for visitor revenue in English cathedrals in 2002 being 30 to 40 pence per visitor (Shackley, 2002: 347).

Shackley (2006:136) argues that the level of donations and other revenuegenerating activities by cathedrals is affected by a range of factors such as their location, size and profile as visitor attractions. Riecken et al. (1994:46) suggest that the individual success of an organisation in raising donations is affected by the high number of charities competing for a share of consumers' income, citing a figure of 140,000 charities in the UK, coupled with a resurgence of materialistic and selfish values among the potential donor population. According to Winter and Gasson (1996:177), the appeal for donations in cathedrals also gives rise to tensions between religious and commercial aims. These tensions are created by the need to highlight the mundane, day-to-day financial and 
commercial needs of the cathedral, while maintaining it as a transcendental 'living place' with a religious purpose, which is freely accessible to worshippers.

This review has highlighted that cathedrals have a pressing need for income generation in order to adequately maintain and manage their buildings, and that visitors present a viable opportunity to raise this much needed income. It is also clear that cathedrals have a limited range of income-generation options from their visitors, and that some of these options may not prove particularly popular or successful with them.

\section{THE LOCAL CONTEXT: CHICHESTER CATHEDRAL}

Chichester is situated on the south coast of England in the county of West Sussex. Chichester Cathedral is located in the centre of the city on the fringe of the pedestrian shopping area and is a Norman construction, consecrated in 1108. One of the Cathedral's strategic management priorities is a commitment not to charge admission fees (Chichester Cathedral, 2007), which limits their access to an immediate and substantial source of income, forcing the cathedral to ensure that alternative income sources such as donations are developed and implemented effectively.

Chichester Cathedral is open daily with no admission charge. Visitors are welcomed at the door by members of a large team of volunteer stewards. Complimentary information leaflets are distributed in a number of languages and a children's guide is provided. Free

guided tours take place twice daily and roving guides are accessible at other times to answer questions (Chichester Cathedral, 2007). 
Several traditional collections boxes are situated around the cathedral for visitor donations and provision is also made for donation by credit card through the use of two electronic donation terminals, similar to automated money dispensers. All donation points and boxes are accompanied by poster displays outlining the cathedral's running and maintenance costs, some citing a daily cost of $£ 3000$ while one gives a $£ 1$-million yearly figure. These posters also highlight the desire to avoid the imposition of visitors' entry fees and the need to protect and restore the building. Visitors are encouraged to make a minimum donation of $£ 5$, with the electronic donation terminals providing options for this amount and five larger sums up to $£ 25$ or 'more', although visitors are also encouraged to donate whatever they can afford. The income generated from donations is used to support the daily running of the building, but one collection box is specifically designated to the Restoration and Development Trust.

Visitor numbers to the cathedral were not accurately quantified until an electronic counter was installed at the entrance door in 2006. 333,000 entrants were recorded in the first year of operation. It is estimated that 191,000 of these were visitors, although this figure is imprecise due to the difficulty of distinguishing 'casual visitors' from all other entrants to the building. In addition, 6,394 people visited as pre-booked groups, 3,344 of whom had a guided tour. During this period the cathedral received $£ 130,930$ in donations from visitors, equating to an average donation of 68 pence per person (Chichester Cathedral, 2007).

\section{METHODOLOGY}


The data included in this paper relates to six questions of a larger survey that explored visitor attitudes towards donations and entrance charges. A self-administered questionnaire was used to collect the data for this study. Two of these questions related to the visibility of signs soliciting donations from visitors, and the fact that donations are being requested for different purposes. Two questions asked visitors if they had made a donation and if so, the method used (card or cash) and the amount donated. Finally, after informing visitors of the cathedral's daily running cost of $£ 3000$, respondents were requested to state what they would consider to be an appropriate minimum donation amount to suggest to visitors. The collected data was supplemented with profiling questions about the respondents, including their age and distance travelled.

Data collection was carried out at Chichester Cathedral over an eleven-day period covering two weekends, one of which was an extended Holiday weekend, and three days midweek. Care was taken to avoid times of formal worship to increase the chance that respondents would be casual visitors. A sample size of 350 respondents was chosen for this research, with the majority of visitors being approached after having completed their visit to the Cathedral but before they left the building. The completed questionnaires were processed using Microsoft Office Excel, with further analysis obtained using data comparison functions on Microsoft Office Access (Microsoft, 2003).

In terms of limitations of this study, it is feasible that questions regarding donations could be interpreted as judgemental, and thus it is possible that respondents could have felt obliged to answer in a particular manner in order to justify themselves (Burns, 2000). For this reason any results relating to donations must be interpreted with care, and any conclusion drawn from these results must be regarded as an indication of the respondent's intentions rather than as hard fact. Questions of this nature rely on the co-operation and 
frankness of respondents and can suffer distortion if participants wish to be seen "in a more favourable light" (Oppenheim, 1992:210). In order to reduce the risk of inaccurate results, the questions concerning donations were asked using both open and closed formats and phrased in language that attached no specific merit to particular answers (Collis and Hussey, 2003).

\section{RESULTS}

This section discusses the findings about respondents' attitudes towards donations and entrance charges in Chichester Cathedral.

\subsection{Visitor Attitudes towards Donation}

Visitors to Chichester Cathedral were highly aware of appeals for donations, with $64 \%$ of visitors noticing several appeals inside the building and $30 \%$ noticing at least one, with only $6 \%$ not noticing any. This indicates that the notice boards and collection boxes inside the cathedral, informing visitors of the cost of running the building and requesting donations, are effective in raising visitor's awareness of the cathedral's financial needs. There did appear to be some confusion, however, over the nature of the appeals, as only $46 \%$ of respondents were aware that there were appeals for different funds, while $48 \%$ had not noticed this distinction.

Almost three quarters of respondents $(71 \%)$ stated to have made a donation towards the cathedral, of which $67 \%$ donated cash and $4 \%$ donated by credit card using the 
electronic donation terminals. Just $23 \%$ of visitors said they had not made a donation and $6 \%$ did not answer this question (Figure 1).

\section{FIGURE 1 HERE}

The proportion of visitors who made donations as a percentage of their age group shows that roughly between $60 \%$ to $75 \%$ of all visitors across all age ranges made donations, with the propensity to donate being higher between the 30 to 69 age ranges, while those under 29 or over 70 were slightly less likely to donate (Figure 2). There were two respondents under 15 years of age who made donations, but this age group was underrepresented in the sample and thus distort the tendencies displayed by the other age groups in Figure 2.

\section{FIGURE 2 HERE}

Unfortunately, $37 \%$ of respondents who made a donation declined to say how much they donated. Figure 3 presents the responses of the $63 \%$ of respondents who were willing to state the amount of donation made, with the most frequent donation amount stated being between $£ 1-£ 2$, which is significantly below the $£ 5$ amount suggested by the Cathedral in its donation posters and under half of the amount of $£ 4$ that Cathedral managers believe visitors should donate in order to attain a sustainable level of funding from donations.

\section{FIGURE 3 HERE}

It is difficult to estimate the total amount of donations given by visitors, as donation amount ranges were used to facilitate respondents' replies, and because $37 \%$ of respondents who made a donation did not wanted to reveal how much did they give. In order to calculate a rough estimate of the total amount donated, the researchers assigned minimum potential donation figures for the respondents who revealed how much they had donated and for those who did not say the amount given. For those visitors who revealed how much they have given, it was assumed that they made the minimum donation within their donation bracket (i.e. $£ 1$ given if $£ 1-£ 2$ bracket was chosen). For those visitors who 
did not revealed the donation given, a $£ 5$ figure was used for those respondents who said they have donated by card, as this is the minimum amount that the card donation terminal displays on its screen; while a 30 pence figure was used for those who donated cash without revealing the amount, as this is a commonly cited figure for average donations received by cathedrals in previous surveys (Winter and Gasson, 1996; Shackley, 2002).

Using the assumptions above, a figure of $£ 589.50$ was regarded as a conservative estimate of the total amount of money that could have been donated by respondents for the period of study, giving a total of $£ 2.32$ per donating respondent $(n=249)$. Considering the total number of respondents $(n=350)$, including those who didn't make a donation, this figure amounts to an average donation of $£ 1.67$ for this particular group of cathedral's visitors. This estimated value is considerably higher than those found in previous studies on cathedral donations, with Winter and Gasson (1996) citing an average figure of about 38 pence for three English cathedrals that didn't charged admission, while Shackley (2002) quotes a figure of 30 to 40 pence per visitor. It is also significantly higher than existing data for donations from visitors at Chichester Cathedral, which amounted to 68 pence per visitor in 2006. Although there are no other estimates of visitor donations in cathedral settings, the estimation made based on the findings of this research is surprisingly high compared to the existing data from other studies. It should be noted that that the cathedral could not provide the actual donation amounts corresponding to the study period. Therefore, there is a lack of triangulation data that may corroborate or challenge this study's results. Thus, the estimated figure for donations presented here must be taken with great caution.

The data collected suggest that the visitor's age has an impact on donation behaviour, with Figure 4 showing that people within the 50-59 age range constituted the largest group of visitors, followed by those in the 60 to 69 age range, while Figure 5 shows 
that these two age groups also constitute the most generous donors. Conversely, the under-15s and over 70s were the least numerous visitors within the study sample, while the visitors giving least generous donations were those aged under 29 years and those over 70 years old.

\section{FIGURE 4 HERE}

Figure 5 indicates that the most generous visitors were those aged between 50 to 69 years, particularly those aged between 50 to 59 , with more than $50 \%$ of this age group donating from $£ 3$ upwards, including nearly $33 \%$ of these respondents who gave upward from $£ 5$. These results are likely to reflect the increase in disposable income typical of middle-age groups whose children have left home on one hand, and also the limited disposable income typical of recently employed or retired age groups on the other.

\section{FIGURE 5 HERE}

Figure 6 shows that the distance travelled to visit the cathedral also has an impact on donation behaviour, with the most generous visitors being local residents, i.e. those travelling less than 25 miles, while the visitors who gave less overall were those who had travelled over 200 miles, including international visitors. However, this pattern of donations again follows the general distance-travelled profile of the respondent sample, with local visitors travelling less than 25 miles being the largest group of the sample (Figure 7).

\section{FIGURE 6 HERE}

FIGURE 7 HERE

\subsection{Suggested Minimum Donation}

The survey explained that the daily cost of running the cathedral is approximately $£ 3,000$, and asked visitors to suggest an appropriate figure for a minimum donation. Almost a third of all respondents (32\%) chose not to answer this question. From those who answered, the 
most common suggested donation figures were $£ 2$ (28\% of respondents) and $£ 1$ (16\%) (Figure 8).

\section{FIGURE 8 HERE}

The donation figures suggested by respondents closely matched the amount actually donated by the majority of visitors and confirms that if Chichester Cathedral were to rely solely on donations for income generation, it would be unlikely to meet the financial expectations of its managers.

\section{DISCUSSION AND RECOMMENDATIONS}

Virtually all visitors surveyed (94\%) were aware of the Cathedral's appeals for donations during their visit, and a significant proportion of them $(71 \%)$ went on to make a donation. In terms of the method used to make a donation, only a very small proportion $(4 \%)$ of visitors used the two electronic donation terminals to do so, with the majority preferring to use the traditional appeal cash boxes distributed through the cathedral. This brings into question the cost-effectiveness of using electronic donation points for fundraising purposes in a cathedral setting, as the cost of their maintenance and security must be funded by the value of the donations made. Although it can be argued that the default settings on the donation screen, starting at a minimum of $£ 5$, will steer most users towards making high-value donations, it is recommended that any organisations using electronic donation points for fund-raising purposes should audit them to assert if they are providing a satisfactory cost/income ratio. Alternatively, the Cathedral could consider the use of mobile phone technology in order to promote and facilitate the process of making a donation. Although there is limited evidence on the effectiveness of mobile-based fundraising technology in tourism settings (Heldt, 2010), it would appear that their use, in 
association with 'bundled goods' (e.g. offers for some services and activities) and the provision of clear information about the purpose and use of the mobile donation request, can lead to increased contributions in low-value donation situations.

The majority of visitors surveyed for this research live within 25 miles of the cathedral and tended to be middle-aged (40 and over), peaking at an age range between 50 to 59 , with this segment also accounting for the majority of the donations. The bulk of donations is coming from what could be considered the cathedral's local community, suggesting that that the older these visitors are and the closer they live to the cathedral, the more likely they are to make a donation and the more generous their donations are likely to be. For this reason, it is recommended that the Cathedral focus their fundraising efforts around their local, middle-aged target population, with this issue being discussed in more detail below along with suggestions on how to increase donations.

The values of the average donation amount given by respondents (£2.32) and the estimated total amount of donations in relation to respondent sample size, including noncontributing visitors (£1.67), seem considerably higher compared with the findings of previous studies. This suggest that respondents may have exaggerated their stated donation amount, hoping that this would show them in a better light in response to a question that they might have perceived to be judgemental.

A strong indication that respondents may have exaggerated their stated donation amount is the fact that the authors manipulated the donation data to test both the possibility that the assumption made for the calculation of card donations using the electronic donation terminals was overly optimistic, or alternatively that the respondents that didn't want to reveal their donation amount (37\% of respondents) might not have made any donation. In 
both cases the amount of donations in relation to respondent sample size still remained above $£ 1.50$ after adjusting the data with these new assumptions, indicating that the large donation figure originates from the data for the actual amounts stated by the respondents rather than from the ranges estimated by the authors. This indicates both the need to treat with caution the stated amount of donations given by respondents, but also highlights the need for any future similar research to conduct donation audits at the same time that visitors are requested to state their donation amounts, so that a reliable triangulation point can be established for data analysis.

The largest proportion of donations made (25\%, £1 - £2 range) and the estimated average donation for the respondent sample (£1.67) are significantly below the $£ 4$ that Chichester Cathedral managers believe visitors should be giving in order to fund the cathedral's running costs. This is a clear indication that visitors do not feel a financial responsibility towards maintaining the cathedral, suggesting that if Cathedral managers continue to rely solely on donations for income generation as currently implemented, they will not be able to achieve a sustainable level of funding from their visitors.

The literature on donations suggest that several options are available to Chichester Cathedral in order to encourage a more consistent level of donations among its visitors, but before specific measures are implemented, its managers need to decide which of the available approaches would be more likely to provide the optimum return on investment. This decision would depend on the socio-demographic characteristics of the visitors being targeted; their motivations to make a donation; the desired nature of the donor and the value of the donation, and the types of marketing activities to promote donation behaviour that are regarded as appropriate at a sacred setting. The way each of these factors is likely to affect donations within the context of Chichester Cathedral is discussed below. 
When discussing the purchase of souvenirs as reminders of the 'sacred space' they are visiting, Swanson (2004:341) argues that managers should identify and assess visitors' motivations to make a purchase, so that their 'heart-strings' can be pulled in order to maximise profit. It is suggested that a similar approach can be taken at Chichester Cathedral to maximise the value of donations, by which the intrinsic, personal meaning for making a donation should be identified and appealed to during fund-raising approaches. This is likely to result in a varied array of donation meanings, from which the most frequent or significant would have to be selected and promoted. Given the context where donations are being requested, one such intrinsic meaning could be the enjoyment of a feeling or atmosphere of sacredness in a cathedral. Thus, a personal meaning by which donations could be promoted is the support and maintenance of the cathedral atmosphere by linking it to the visitors' sense of place sacredness.

Other management measures that Chichester Cathedral could potentially use in order to increase donations might include the mapping of donation service experiences and the implementation of Customer Relationship Management (CRM) of high value donors. According to Polonsky and Sargeant (2007:461) this approach would require the segmentation of donors by identifying their specific interests to make a donation, and then targeting those donors that are likely to make higher donations by providing a range of benefits aimed at rewarding their donations (Kim and Crompton, 2002). This approach would result on a high return on investment by enabling managers to target specific visitor segments with appropriate solicitations, while minimising donor attrition rates and maximising donor lifetime value (Polonsky and Sargeant, 2007:460). However, although an improvement of the donation service experience advocated by this approach has the potential to benefit all visitors, for example by making the process of donating easier by 
using mobile-enabled donation technology, the CRM element of this approach would have to be sensitively implemented in a cathedral setting in order to avoid creating the perception of deferential or unfair treatment of visitors according to the amount of money they are willing to donate.

There are further donation maximisation strategies that the authors regard as suitable and which Chichester Cathedral could consider implementing. One of these is the targeting of visitors' altruism by segmenting and targeting spiritual visitors with appropriate advertisement messages that contain a generic spiritual appeal (Ranganathan and Henley 2008:8). Alternatively, Cathedral managers could identify and target donors with a favourable impression of the Cathedral's organisational values (particularly improving society) and with specific personality trait factors (low hedonism, empathy, valuing warm relations, achievement and inner self-esteem) that make them likely to donate consistently and generously (Bennett, 2003:26).

Something that becomes clear from the suggested donation management approaches discussed above is that Chichester Cathedral needs to develop a detailed understanding of who their donors are and move away from the generically-focused, upkeep costs-related charitable appeals. Instead, Cathedral managers should both target specific population segments more effectively and use charitable appeals that are more pertinent to, and effective with, the desired donor segments. Presently, the Cathedral does not collect information about their visitors' socio-demographic characteristics or their motivations to make a donation. As the majority of donation-increasing approaches discussed in this paper consider both of these elements as essential in order to develop more targeted messages, it is recommended that the Cathedral should urgently develop a 
systematic information-gathering approach that identifies their donors' motivations and socio-demographic characteristics.

However, at this stage, it would also be relevant for Cathedral managers to consider what form of charity marketing would be most appropriate to use on a sacred setting. Stevens et al. (1995) argue that members of the clergy tend to consider any church-related marketing activities as inappropriate, particularly if they lack a business employment background prior to church life. They also found that both the clergy and the general public tend to perceive marketing activities aimed at increasing donations to the church as being inappropriate. They conclude that church-related marketing messages should be of a personal, non-intrusive nature, and should carry high emphasis on personal choice that reflects religious individualism but that has limited content and substance in terms of religious dogma (Stevens et al., 1995:95).

\section{CONCLUSION}

This research has demonstrated that a donations-only approach, as implemented at present, is insufficient for Chichester Cathedral to generate a sustainable funding for their upkeep and maintenance. However, the authors believe that more targeted and sustained efforts at promoting donation behaviour among visitors are likely to increase both the frequency and amounts of donations. In order to implement these targeted efforts, Chichester Cathedral would first need to develop a much deeper understanding of who their donors are and their intrinsic motivations to contribute financially to the cathedral. Ultimately, it is possible that a donation-only approach might not ever fully meet the financial 
needs of such complex, difficult to maintain infrastructure and additional fundraising measures will have to be eventually implemented.

\section{REFERENCES}

ALVA. 2014. Visits made in 2013 to attractions in membership with ALVA. Association of Leading Visitor Attractions. Available at http://www.alva.org.uk/details.cfm? $p=423$ (accessed 20 June 2014).

Bennett R. 2003. Factors underlying the inclination to donate to particular types of charity. International Journal of Nonprofit and Voluntary Sector Marketing 8(1): 12-29.

Boniface P. 1995. Managing Quality Cultural Tourism. Routledge, London.

Canterbury Cathedral. 2007. 'Save Canterbury Cathedral' Appeal Information. Available at http://www.canterbury-cathedral.org/fundraising/index.aspx $\quad$ (accessed 20 November 2007).

Chichester Cathedral. 2007. Annual Report March 2007. Available at http://chichestercathedral.co.uk/dyn/_folder3/AnnualReportforwebsite.pdf. (accessed 2 November 2007).

Churches Tourism Association. 2007. Information on VisitBritain USA website. Available at http://www.churchestourismassociation.info/index.php?option=comwrapper\&ltemid=107. (accessed 16 November 2007). 
Collis J, Hussey R. 2003. Business Research: A Practical Guide for Undergraduate and Postgraduate Students. Palgrave Macmillan, Basingstoke.

Fladmark J. 1998. In Search of Heritage as Pilgrim or Tourist? The Robert Gordon University, Aberdeen.

Heldt T. 2010. Financing recreational infrastructure with micropayments and donations: a pilot study on cross-country ski track preparations in Sweden. Scandinavian Journal of Hospitality and Tourism 10(3): 386-394.

Kim S, Crompton J. 2002. The influence of selected behavioural and economic variables on perceptions of admission price levels. Journal of Travel Research 41: 144-152.

Lincoln Cathedral. 2009. Fundraising and Finance. Available at http://www.lincolncathedral.com/ (accessed 28 July 2009).

Microsoft. 2003. Microsoft Office Professional Edition. Microsoft Corporation, Redmond.

Oppenheim A.N. 1992. Questionnaire Design, Interviewing and Attitude Measurement. Pinter Publishers Ltd, London.

Polonsky M, Sargeant A. 2007. Managing the donation service experience. Non-Profit Management and Leadership 17(4): 459-476. 
Ranganathan S, Henley W. 2008. Determinants of charitable donation intentions: a structural equation model. International Journal of Nonprofit and Voluntary Sector Marketing 13(1): 1 -11.

Riecken G, Babakus E, Yavas U. 1994. Facing resource attraction challenges in the nonprofit sector: a behaviouristic approach to fund raising and volunteer recruitment. Journal of Professional Services Marketing 11(1): 45-70.

Shackley M. 2001. Managing Sacred Sites. Thomson, London.

Shackley M. 2002. Space, Sanctity and Service; the English Cathedral as Heterotopia. International Journal of Tourism Research 4: 345-352.

Shackley M. 2006. Cost and benefits: the impact of cathedral tourism in England. Journal of Heritage Tourism 1(2): 133-141.

Stevens R, Loudon D, Paschal R. 1995. Clergy evaluations of the appropriateness of marketing activities: a re-examination. Journal of Ministry Marketing \& Management 1(1): 85-96.

Swanson K. 2004. Tourists' and retailers' perceptions of souvenirs. Journal of Vacation Marketing 10(4): 363-367.

The Giving Campaign. 2007 A Blueprint for Giving. Available at http://www.givingcampaign.org.uk/images/uploaded/blueprint_for_giving.pdf. (accessed 20 November 2007). 
Voase R. 2007. Visiting a Cathedral: The Consumer Psychology of a 'Rich Experience'. International Journal of Heritage Studies 13(1): 41-55.

Winter M, Gasson R. 1996. Pilgrimage and tourism: cathedral visiting in contemporary England. International Journal of Heritage Studies 2(3): 172-182.

York Minster. 2009. York Minster Fund donations. Available at http://www.yorkminster.org/donate/ (accessed 28 July 2009).

Figure 1: Method of Donation (Percentage of Visitors) 


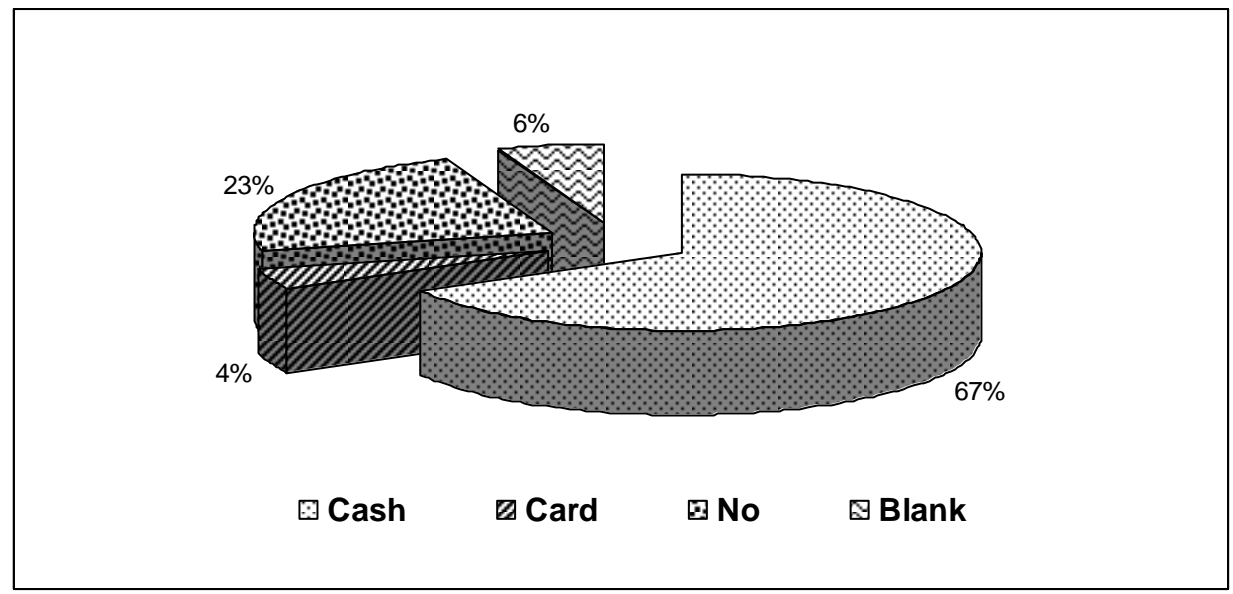

Figure 2: Proportion of visitors by age who made a donation (\%)

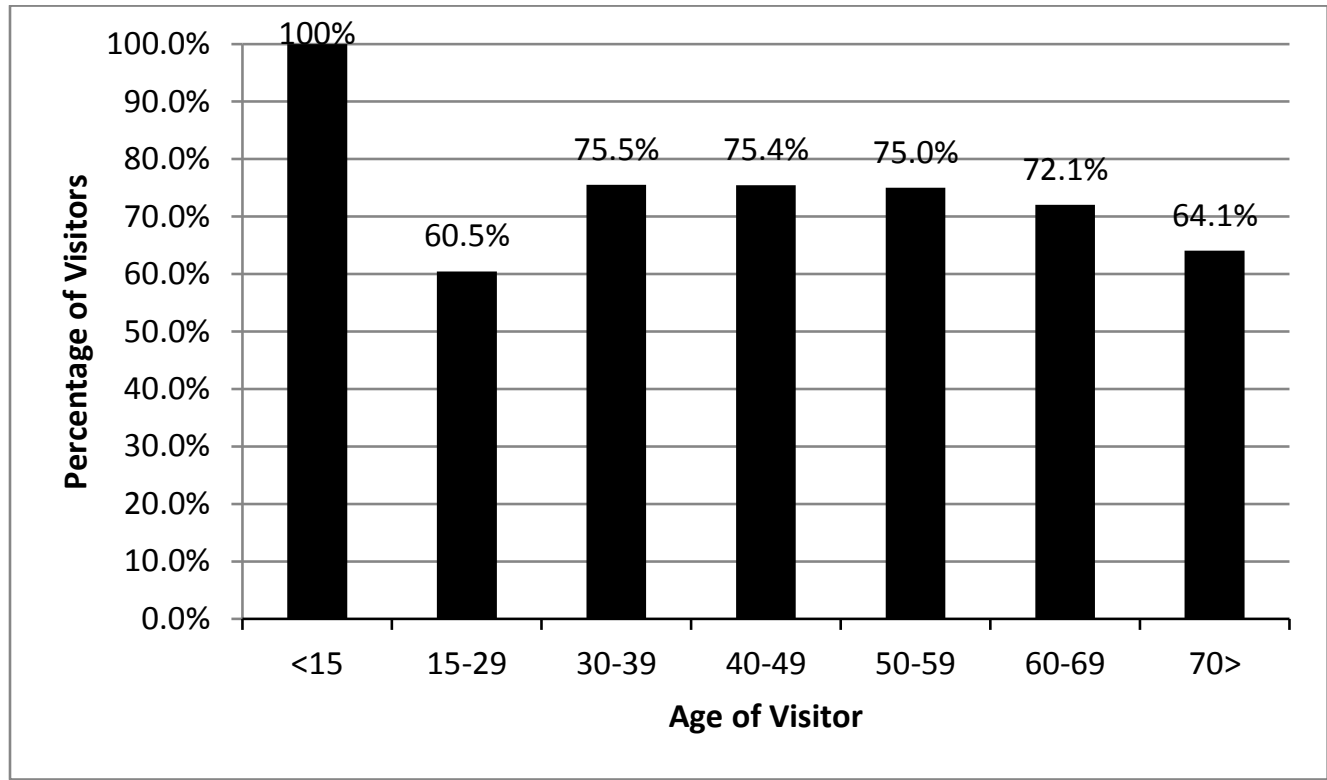

Figure 3: Amount of Donation Made By Visitors (Percentage of Visitors) 


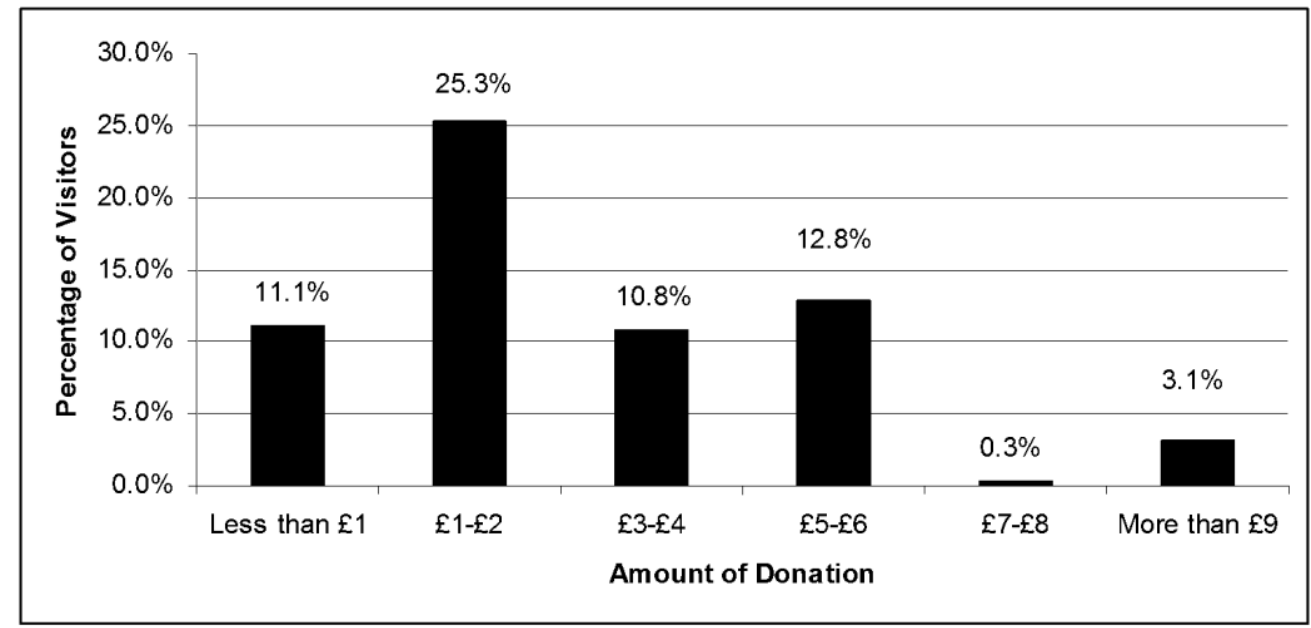

Figure 4: Visitor Profile by Age (\%)

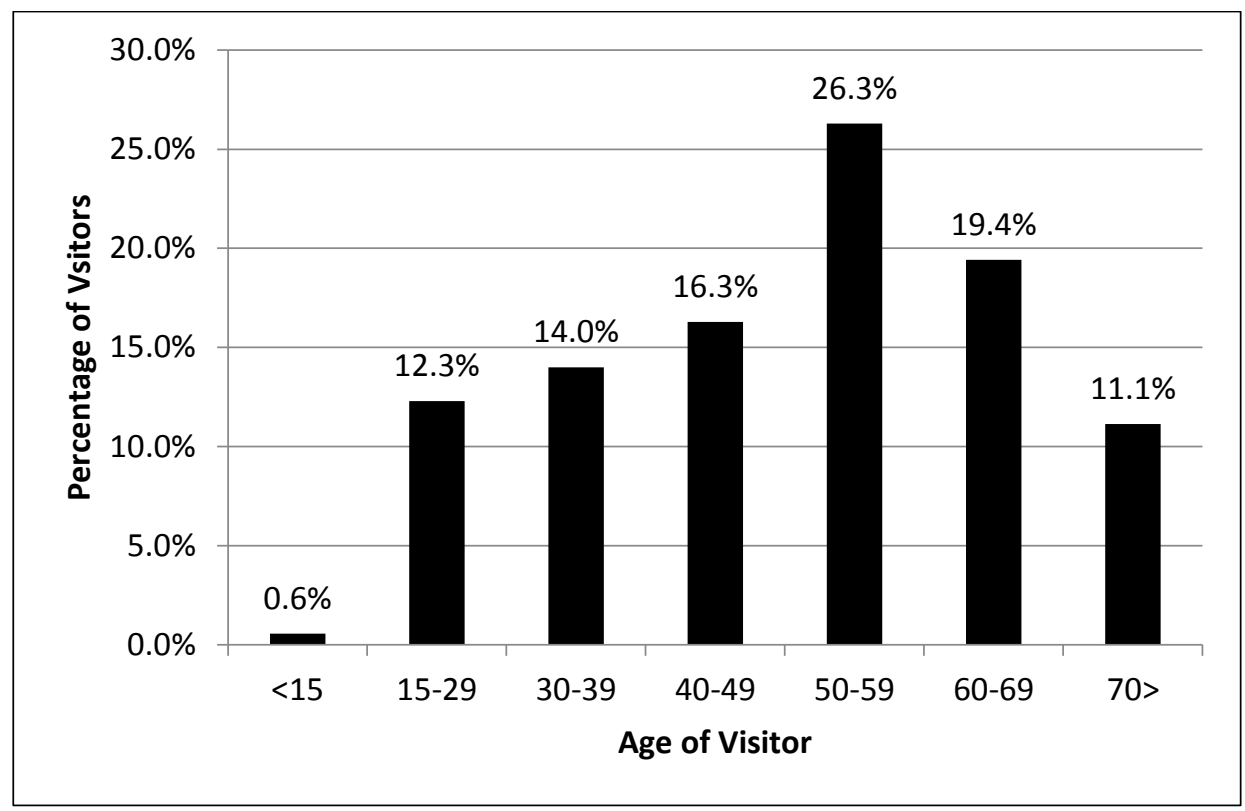

Figure 5: Amount of Donation Made (Total Number of Visitors by Age) 


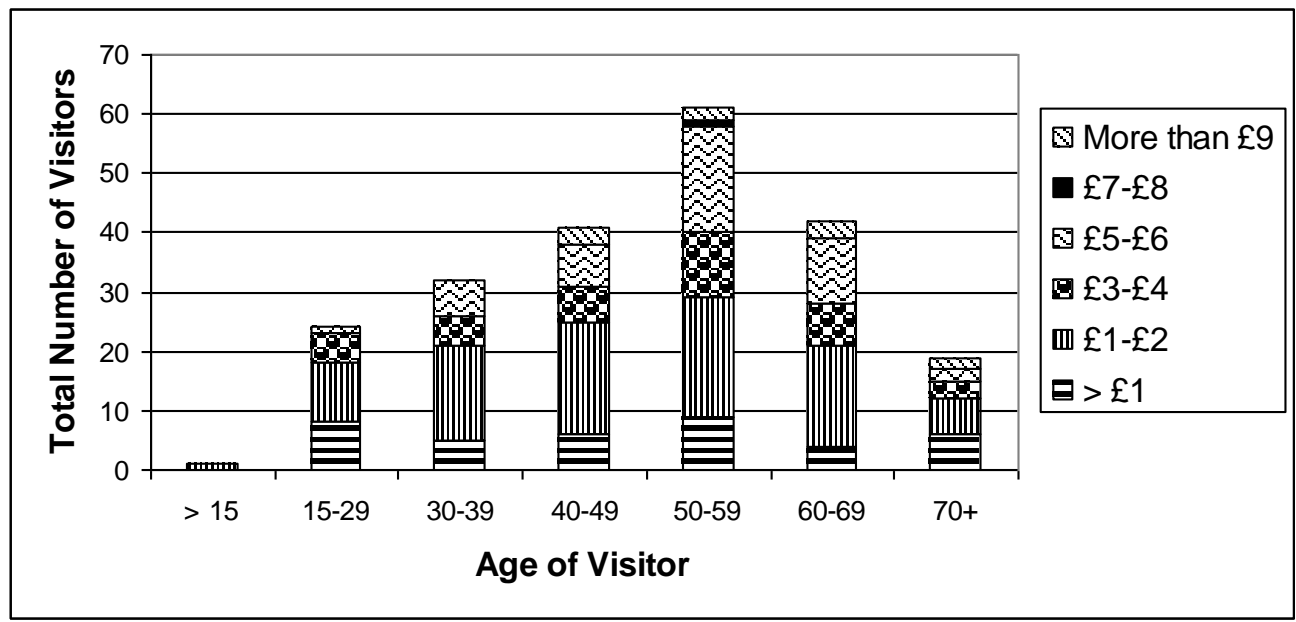

FIGURE 6

Figure 6: Amount of donation made by respondents, broken down by distance travelled

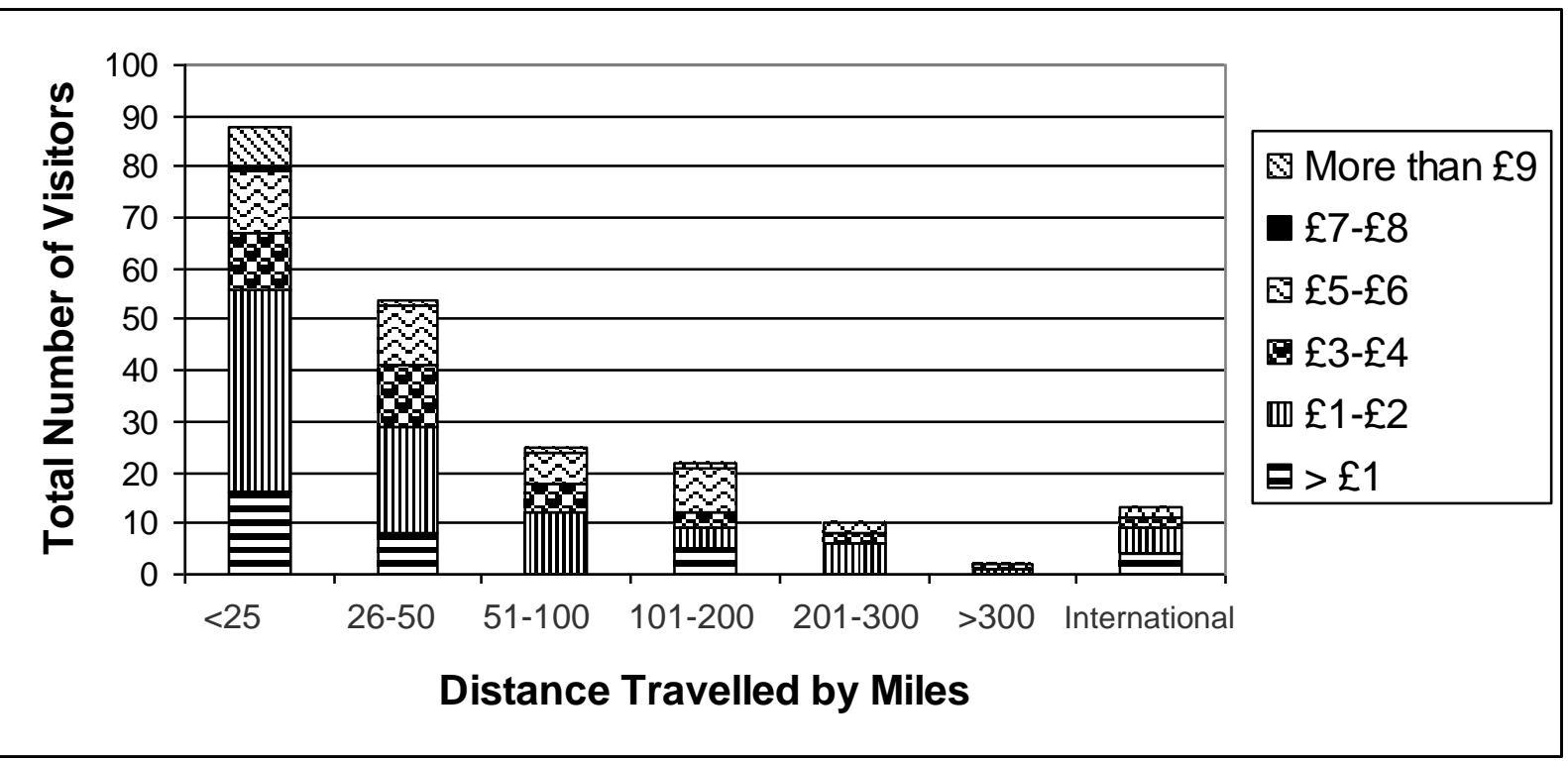


Figure 7: Visitor Profile by Distance Travelled

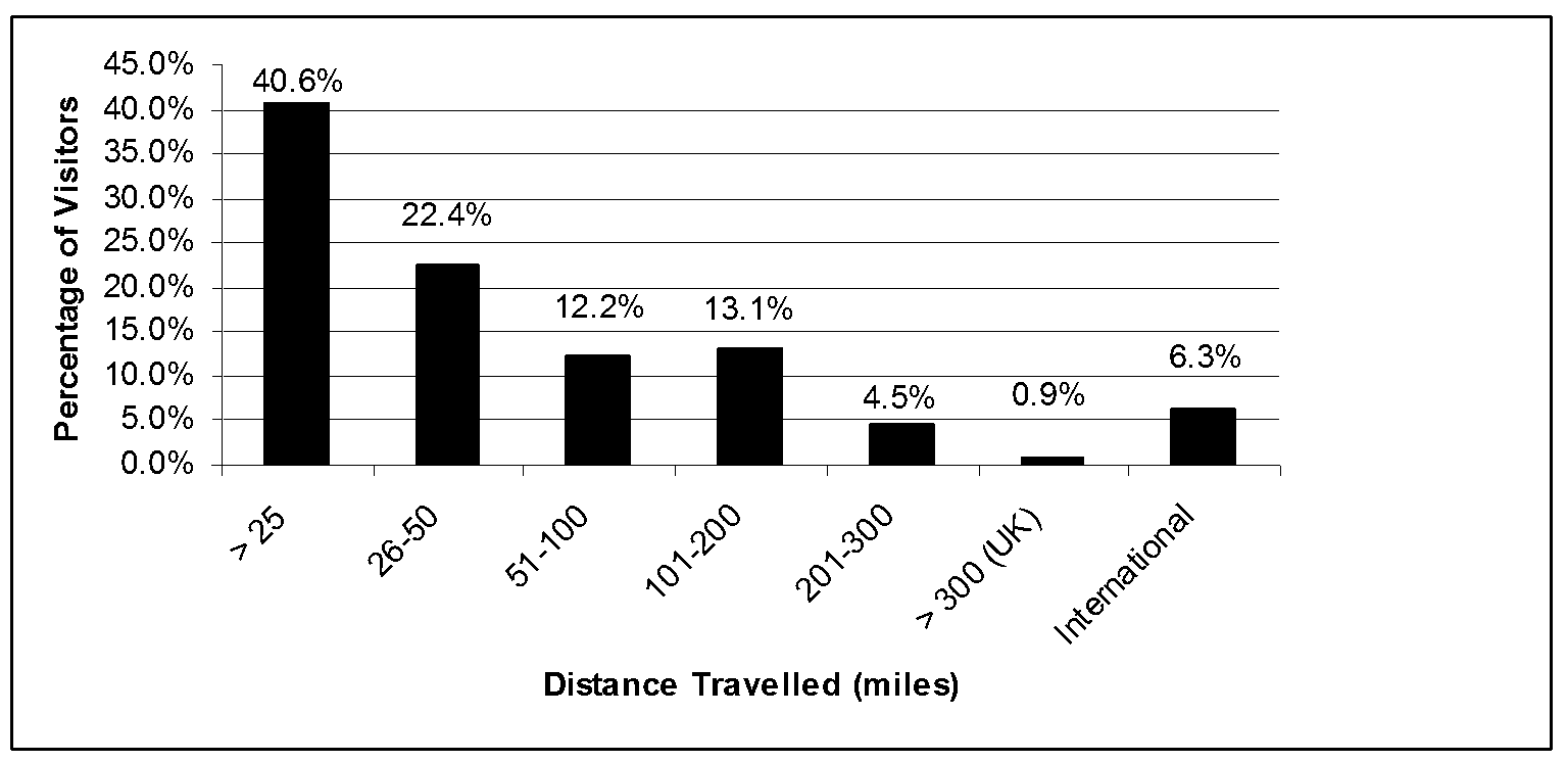

Figure 8: Suggested Amount for Donations (Percentage of Visitors)

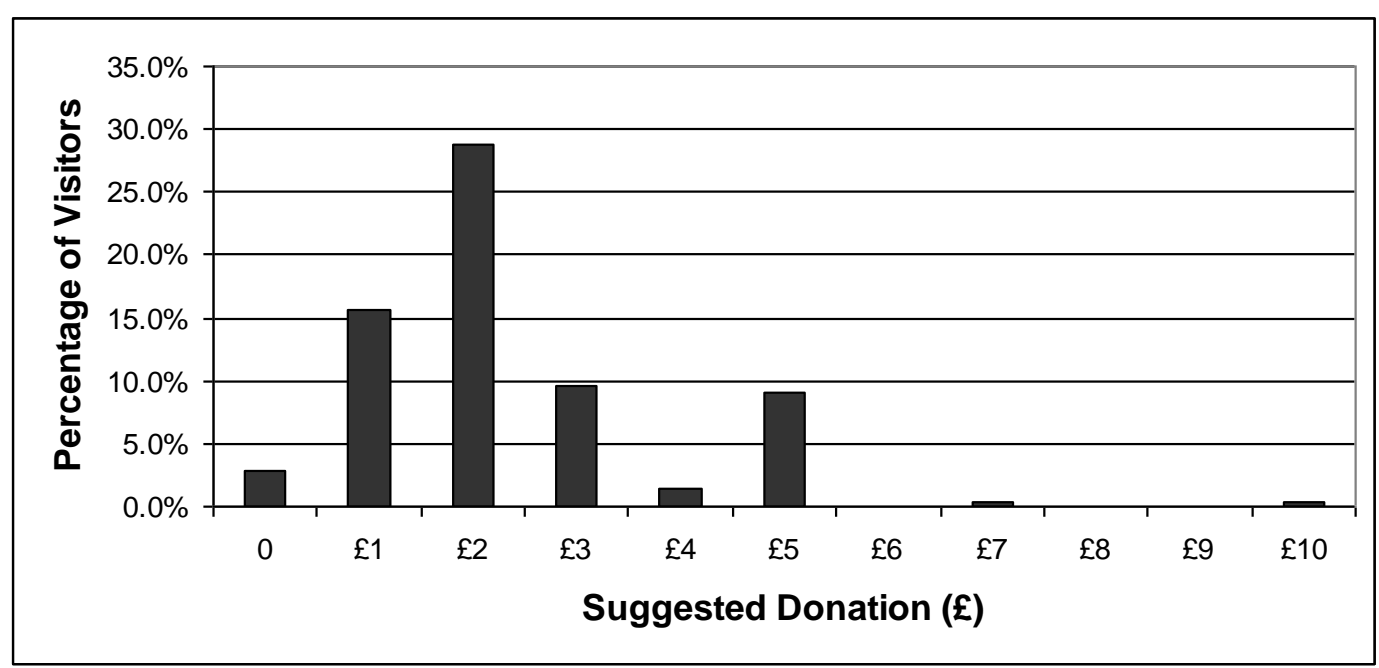

